\title{
SÍNTESIS DE PARTÍCULAS DE MgO Y SU INCORPORACIÓN EN CELDAS SOLARES SENSIBILIZADAS A BASE DE TiO
}

\author{
O. Rojas ${ }^{\mathrm{a}}$, C. Giannini ${ }^{\mathrm{b}}$, D. Siliqi ${ }^{\mathrm{b}}$, D. Altamura ${ }^{\mathrm{b}}$, F. Paraguay-Delgado ${ }^{\mathrm{c}}$, J.L. Solís ${ }^{\mathrm{a}}$, \\ M.M. Gómez*a
}

\begin{abstract}
RESUMEN
Se ensamblaron y se caracterizaron celdas solares basadas en $\mathrm{TiO}_{2}$ nanoestructurado modificado con $\mathrm{MgO}\left(\mathrm{TiO}_{2}-\mathrm{MgO}\right)$; las cuales fueron sensibilizadas con el colorante N719. La modificación de las películas de $\mathrm{TiO}_{2}$ con $\mathrm{MgO}$ se realizó empleando suspensiones de diferentes concentraciones de $\mathrm{Mg}(\mathrm{OH})_{2}$ preparado a partir de una solución acuosa de nitrato de magnesio. Una gota de la suspensión se colocó sobre el recubrimiento del $\mathrm{TiO}_{2}$, y luego todo el sistema se sinterizó a $530 \mathrm{oC}$ durante $30 \mathrm{~min}$. Se obtuvieron celdas sin sellar y celdas selladas, estas últimas alcanzaron una eficiencia de 4,4\%, lo que representó un incremento del $69 \%$ con relación a la celda sellada sin modificar, que mostró una eficiencia de 2,6\%.

Además, se realizaron medidas de la eficiencia solar de una celda sellada bajo iluminación y en oscuridad, y se encontró que la eficiencia disminuyó 19\% luego de 22 días en oscuridad, y $76 \%$ después de 2 días bajo iluminación.
\end{abstract}

Palabras clave: $\mathrm{TiO}_{2}, \mathrm{MgO}$, nanopartículas, celdas solares sensibilizadas.

\section{SYNTHESIS OF $M g O$ NANOPARTICLES AND THEIR INCORPORATION INTO $\mathrm{TiO}_{2}$ SENSIBILIZED SOLAR CELLS}

\begin{abstract}
Nanoestructured $\mathrm{TiO}_{2}$ solar cells modified with $\mathrm{MgO}\left(\mathrm{TiO}_{2}-\mathrm{MgO}\right)$ were assembled and characterized; they were sensitized with N791 dye. The $\mathrm{MgO}$ modification of the $\mathrm{TiO}_{2}$ films was performed using suspensions with different concentrations of $\mathrm{Mg}(\mathrm{OH})_{2}$ prepared from magnesium nitrate in aqueous solution. One drop of the suspension was placed on top of the film and then was sintered at $530{ }^{\circ} \mathrm{C}$ during $30 \mathrm{~min}$. Unsealed cells and sealed cells were obtained, the latter achieved an efficiency of $4.4 \%$, representing an increase of $69 \%$ compared to the unmodified sealed cells, which showed an efficiency of $2.6 \%$.

\footnotetext{
a Facultad de Ciencias, Universidad Nacional de Ingeniería, Av. Túpac Amaru 210, Lima25, Perú, mgomez@uni. edu.pe

b Institute of Crystallography, Italian National Research Council, Via Amendola 122/O, Bari, Italia

c Centro de Investigación en Materiales Avanzados S. C., CIMAV, Miguel de Cervantes 120, Chihuahua, Chih. México.
} 
Solar efficiency measurements were also performed in darkness and under illumination. It was found that the efficiency diminished $19 \%$ in darkness after 22 days, but under illumination diminished $76 \%$ in two days.

Key words: $\mathrm{TiO}_{2}, \mathrm{MgO}$, nanoparticles, sensitized solar cells.

\section{INTRODUCCIÓN}

Las celdas fotovoltaicas son la unidad básica de los paneles fotovoltaicos, ellas convierten la energía solar directamente en energía eléctrica. En la actualidad, las celdas de silicio son las más utilizadas, pero ellas aún siguen siendo costosas en su proceso de fabricación. También se han desarrollado otras tecnologías de celdas solares como las celdas a base de películas delgadas constituidas por teluro de cadmio, diseleniuro de cobre indio y galio, pero ellas contienen elementos de alta toxicidad ${ }^{1}$.

En el año 1991 se presentaron las celdas sensibilizadas a base de $\mathrm{TiO}_{2}$ nanoestruturado sensibilizado con colorante ${ }^{2}$. Estas celdas presentan muchas ventajas, entre las que destacan el bajo costo de su producción así como su no toxicidad. Sin embargo, estas celdas difieren notoriamente de las celdas de silicio, porque el mecanismo de obtención de electricidad pasa por un mecanismo distinto, dado que el proceso de colección de los fotones provenientes del sol son capturados por el colorante y luego son inyectados en el semiconductor ${ }^{3}$, así los procesos de recombinación disminuyen con relación a las celdas de silicio. Actualmente, este tipo de celdas vienen siendo muy estudiadas, y cada uno de sus componentes son motivo de amplios estudios. Específicamente, una de las opciones que se han estudiado es la posibilidad de modificar el electrodo de trabajo de $\mathrm{TiO}_{2}$ con otro óxido como $\mathrm{NiO}^{4,5}, \mathrm{ZnO}^{6}$ y $\mathrm{MgO}^{7}$, entre otros.

En el presente trabajo se procedió a modificar el recubrimiento de $\mathrm{TiO}_{2}$ con $\mathrm{MgO}$ y se estudió la dependencia de la eficiencia de las celdas para diferentes concentraciones del modificante. También se realizaron análisis estructurales y morfológicos de las partículas del $\mathrm{MgO}$ por diferentes técnicas, como difracción de rayos $\mathrm{X}$ y microscopía electrónica.

\section{PARTE EXPERIMENTAL}

La síntesis de $\mathrm{MgO}$ fue a partir de $\mathrm{Mg}\left(\mathrm{NO}_{3}\right)_{2} 6 \mathrm{H}_{2} \mathrm{O}$. La selección de esta sal hidratada facilitó la solubilidad en un medio acuoso y favoreció una mejor homogeneización de la solución a obtener. Se prepararon soluciones de $100 \mathrm{ml}$ de concentración $0,02 \mathrm{M}$, de $\mathrm{Mg}\left(\mathrm{NO}_{3}\right)_{2} 6 \mathrm{H}_{2} \mathrm{O}$. Para obtener el hidróxido de magnesio $\mathrm{Mg}(\mathrm{OH})_{2}$, se agregó gota a gota amoniaco $\mathrm{NH}_{4} \mathrm{OH}$ concentrado. Durante la síntesis se empleó agitación constante, se mantuvo la temperatura a $50{ }^{\circ} \mathrm{C}$ y se controló el $\mathrm{pH}$ a 10.

El precipitado obtenido se lavó tres veces con centrifugación, empleando agua desionizada 
y se secó a $100{ }^{\circ} \mathrm{C}$ por $2 \mathrm{~h}$. El polvo de $\mathrm{Mg}(\mathrm{OH})_{2}$ una vez seco fue llevado a suspensión nuevamente para preparar diferentes concentraciones, y otra cantidad se llevó a un tratamiento térmico de $530{ }^{\circ} \mathrm{C}$ durante 40 min para obtener las partículas de $\mathrm{MgO}$.

Las reacciones que se postulan durante la síntesis son las siguientes: Formación del $\mathrm{Mg}(\mathrm{OH})_{2}$ :

$$
\mathrm{Mg}\left(\mathrm{NO}_{3}\right)_{2} 6 \mathrm{H}_{2} \mathrm{O}+2 \mathrm{NH}_{4} \mathrm{OH} \stackrel{50^{\circ} \mathrm{C}}{\mathrm{Agitación}} \mathrm{Mg}(\mathrm{OH})_{2} \downarrow+2 \mathrm{NH}_{4} \mathrm{NO}_{3}+6 \mathrm{H}_{2} \mathrm{O}
$$

Descomposición térmica del $\mathrm{Mg}(\mathrm{OH})_{2}$ a $\mathrm{MgO}$ :

$$
\mathrm{Mg}(\mathrm{OH})_{2} \stackrel{530^{\circ} \mathrm{C}}{\longrightarrow} \mathrm{MgO}+\mathrm{H}_{2} \mathrm{O}
$$

Para obtener los electrodos de trabajo nanoestructurados de $\mathrm{TiO}_{2}$ se elaboró una pasta empleando $1 \mathrm{~g}$ de $\mathrm{P} 25$ y $4 \mathrm{ml}$ de etanol, la cual se depositó sobre un sustrato conductor por medio de la técnica del doctor blade ${ }^{8}$. Los sustratos conductores empleados fueron películas delgadas de óxido de flúor dopado con estaño (FTO). Estos substratos conductores se lavaron utilizando detergente, agua destilada y etanol en sonicación por más de 6 min. Luego fueron secados a $450{ }^{\circ} \mathrm{C}$ durante $15 \mathrm{~min}$. Luego el recubrimiento de $\mathrm{TiO}_{2}$ se sinterizó a $530{ }^{\circ} \mathrm{C}$ por un tiempo de $30 \mathrm{~min}$. Por lo general, el área depositada de óxido de titanio fue entre 0,25 y $1 \mathrm{~cm}^{2}$. Seguidamente, se enfrió el sistema hasta $80^{\circ} \mathrm{C}$ y el recubrimiento de $\mathrm{TiO}_{2}$ se colocó en una solución de $0,05 \mathrm{mM}$ del colorante N719 durante $14 \mathrm{~h}$. El enjuague del colorante no anclado en la superficie del $\mathrm{TiO}_{2}$ se removió con lavados sucesivos de etanol. Este último procedimiento constituyó el proceso de sensibilización por medio del cual la molécula del colorante quedó anclada al $\mathrm{TiO}_{2}$. Este procedimiento se realizó para obtener las celdas no modificadas.

Las películas nanoestructuradas de $\mathrm{TiO}_{2}$, modificada con $\mathrm{MgO}\left(\mathrm{TiO}_{2}-\mathrm{MgO}\right)$, se prepararon al aplicar una gota de la suspensión de $M g(O H)_{2}$. La modificación se llevó a cabo con suspensiones de diferentes concentraciones, luego estas películas fueron sinterizadas y sensibilizadas análogamente al caso en el que no fueron modificadas.

Para la preparación de los contraelectrodos se emplearon también sustratos conductores de FTO, en que se realizaron dos orificios y luego estos contraelectrodos fueron lavados como en el proceso seguido para la preparación de los electrodos de trabajo. Luego se depositó una pasta de platino por la técnica del doctor blade y se sinterizó a $390{ }^{\circ} \mathrm{C}$ durante $20 \mathrm{~min}$. En este trabajo se usó el electrólito líquido ioduro/triyoduro adquirido de la empresa Dyesol, el cual se caracteriza por su baja viscosidad y alta conductividad iónica.

El sellado de las celdas es un aspecto importante en su fabricación, ya que mediante el sellado se previene la fuga del electrólito y la evaporación del solvente. Como sellante se empleó el material comercial Surlyn MS004610 de la empresa Dyesol, el cual se caracteriza por ser una película transparente y flexible con un espesor uniforme, estable químicamente y con buenas propiedades mecánicas. 
Luego del sellado del electrodo de trabajo y el contraelectrodo se introdujo el electrólito por uno de los orificios, posteriormente estos orificios son sellados, también con otra lámina del sellante. El sellado se realizó con una pistola de aire caliente a una temperatura de aproximadamente $120^{\circ} \mathrm{C}$. Se evaluó la dependencia de la eficiencia de una celda solar sellada a base de $\left(\mathrm{TiO}_{2}-\mathrm{MgO}\right)$ con el tiempo. Este estudio se realizó en una cámara oscura que contó con una lámpara Ultra-Vitalux OSRAM $(220 \mathrm{~V} \text { y } 300 \mathrm{~W})^{9}$. La celda fue expuesta a iluminación y se mantuvo en oscuridad en diferentes lapsos durante 27 días. Durante las horas de iluminación, la irradiancia sobre la celda fue de $1000 \mathrm{~W} / \mathrm{m}^{2}$, la cual fue medida con un radiómetro Kipp \& Zonen $\mathrm{CMP}^{11}$.

\section{RESULTADOS Y DISCUSIÓN}

En esta sección se presentarán primero los datos correspondientes a las partículas de $M g O$ $\mathrm{y}$ su estudio estructural por difracción de rayos $\mathrm{X}$ y microscopía electrónica, seguidamente se mostrarán los datos fotoelectroquímicos de los electrodos modificados $\mathrm{TiO}_{2}-\mathrm{MgO}$, y finalmente se abordará la eficiencia como celda solar de las celdas modificadas, constituidas por los electrodos de trabajo modificados $\mathrm{TiO}_{2}-\mathrm{MgO}$ para diferentes concentraciones de $\mathrm{MgO}$.

\section{Análisis de las partículas de $\mathrm{MgO}$}

Para la preparación de los electrodos modificados se emplearon muy pequeñas cantidades de $M g O$. La determinación de la presencia del $\mathrm{Mg}$ en la superficie de ellos se realizó mediante fluorescencia de rayos X, para lo cual se empleó un espectrómetro FRX que contó con: un tubo de rayos X cuyo ánodo fue de Gadolinio Modelo Epsilon 5, un blanco secundario de $\mathrm{Al}_{2} \mathrm{O}_{3}$ y un detector semiconductor de $\mathrm{Si}(\mathrm{Li})$ de $140 \mathrm{eV}$ de resolución para $5,89 \mathrm{keV}$ de energía. El electrodo modificado sin sensibilización fue colocado directamente en el portamuestra del espectrofotómetro. Se encontró una concentración de 149 ppm de $\mathrm{Mg}$ en la superficie analizada. Sin embargo, esta técnica no brinda información de la estructura cristalina en la que se encuentra. Por ello para aproximarse a la estructura y morfología del $\mathrm{MgO}$ en la superficie de los electrodos de $\mathrm{TiO}_{2}$, se preparó polvo de $\mathrm{MgO}$ y se sintetizó a $530{ }^{\circ} \mathrm{C}$, que fue la misma temperatura que se usó para la sinterización de los electrodos. Luego se hicieron estudios por diversas técnicas. Para las medidas de difracción de rayos $\mathrm{X}$ se usó un difractómetro Rigaku Miniflex Desktop, con una fuente de radiación $\mathrm{CuK} \alpha 1(\lambda=$ $0,15405 \mathrm{~nm}$ ) a $30 \mathrm{kV}, 20 \mathrm{~mA}$ y con una velocidad de barrido de $3 \% \mathrm{~min}$. La figura 1 muestra el difractograma obtenido, los picos observados a los ángulos $2 \theta$ iguales a $36,80^{\circ}, 42,85^{\circ}$, $62,23^{\circ}, 74,56^{\circ}$ y $78,52^{\circ}$ fueron asignados a las reflexiones (111), (200), (220), (311) y (222) de la fase periclasa correspondiente a la tarjeta $\mathrm{N}^{\circ} 00-045-0946$ de la JCPDS.

El tamaño promedio de los dominios cristalinos se calculó usando el programa TOPAS, el cual emplea el Método de Rietveld ${ }^{10}$. Mediante este procedimiento se ajustó el difractograma usando la función Voigt y se empleó el ancho integral de los picos desarrollada por Stokes y Wilson ${ }^{11}$ en un tratamiento más generalizado del ensanchamiento del pico que es independiente de la forma del cristalito. El resultado del ajuste determinó un tamaño de cristalito de $16 \mathrm{~nm}$. 


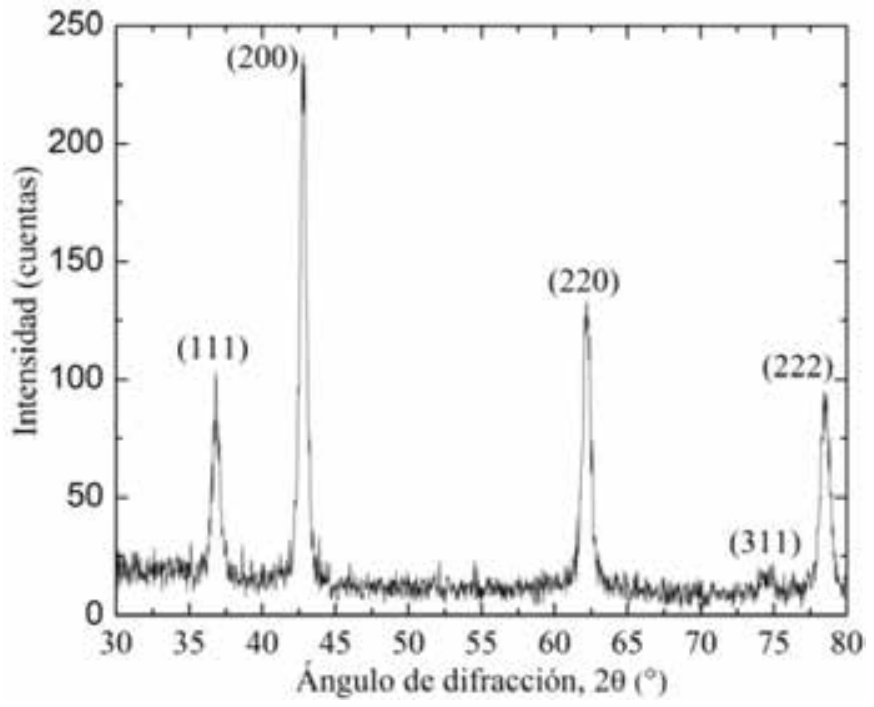

Figura 1. Difractograma de rayos $\mathrm{X}$ de $M g O$ en polvo.

El estudio estructural de las nanopartículas también se abordó con el análisis de microscopía electrónica realizado con el microscopio electrónico de transmisión Jeol modelo JEM 220FS operado a $200 \mathrm{kV}$. Las micrografías STEM (de los términos en inglés Scanning Transmission Electron Microscope) de la figura 2 muestran las características morfológicas de las partículas de $\mathrm{MgO}$, la figura 2a muestra la imagen de campo claro y la figura $2 \mathrm{~b}$ muestra la imagen en contraste $\mathrm{Z}(\mathrm{Z}$ = número atómico) de la misma zona. Se observan en las imágenes conglomerados cristalinos con tamaños del orden de $250 \mathrm{~nm}$. Los dominios cristalinos que constituyen a estos conglomerados no se resuelven claramente, pero se observa que existen cristales muy pequeños, menores a $50 \mathrm{~nm}$.

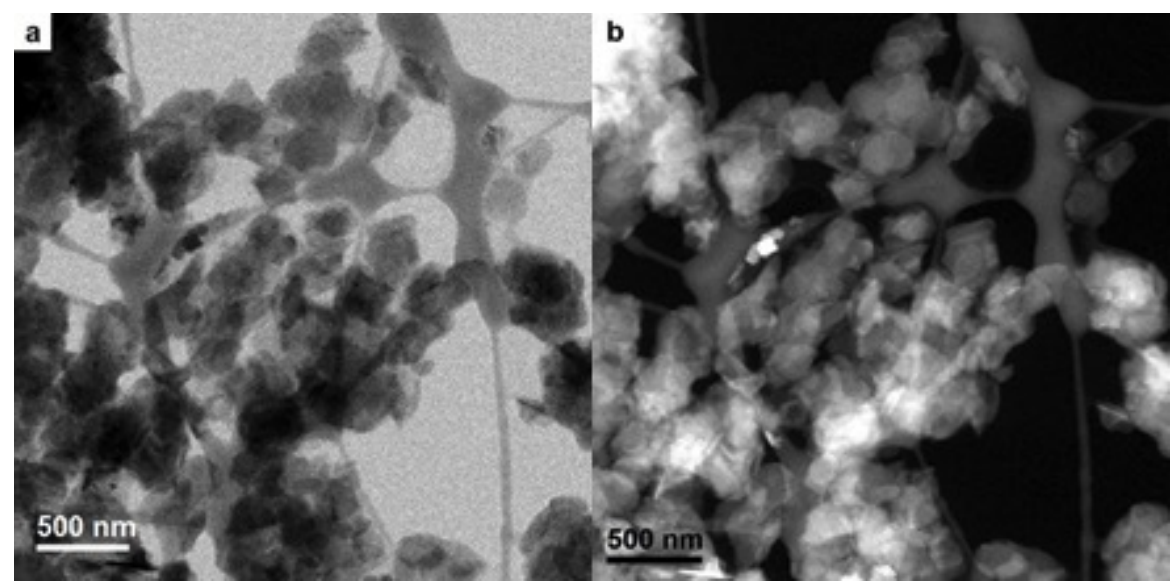

Figura 2. Micrografías STEM de las partículas de $M g O$ para una magnificación de $40 \mathrm{kX}$ : (a) campo claro y (b) contraste $\mathrm{Z}$. 
El estudio de los conglomerados cristalinos del $\mathrm{MgO}$ a mayores magnificaciones muestra que ellos se presentan como láminas apiladas. Las imágenes se muestran en la figura 3 en las que se observan dos enfoques de los apilamientos: frontal y lateral.

Los dominios cristalinos vistos frontalmente se muestran muy apilados unos sobre otros, como lo corroboran las imágenes de la vista lateral, donde se puede identificar que el espesor de las láminas es del orden de $60 \mathrm{~nm}$ y el tamaño de los cristales que las conforman es de tamaño menor a $20 \mathrm{~nm}$, lo que está en concordancia con la información obtenida por DRX. Los patrones de difracción de electrones muestran la conformación de los conglomerados por nanocristales, las intensidades de las reflexiones en la dirección (200) no son las mismas para la vista frontal y lateral. Así, también, la forma de las intensidades muestra un cierto grado de texturización, la cual está en concordancia con los aglomerados de forma laminar.

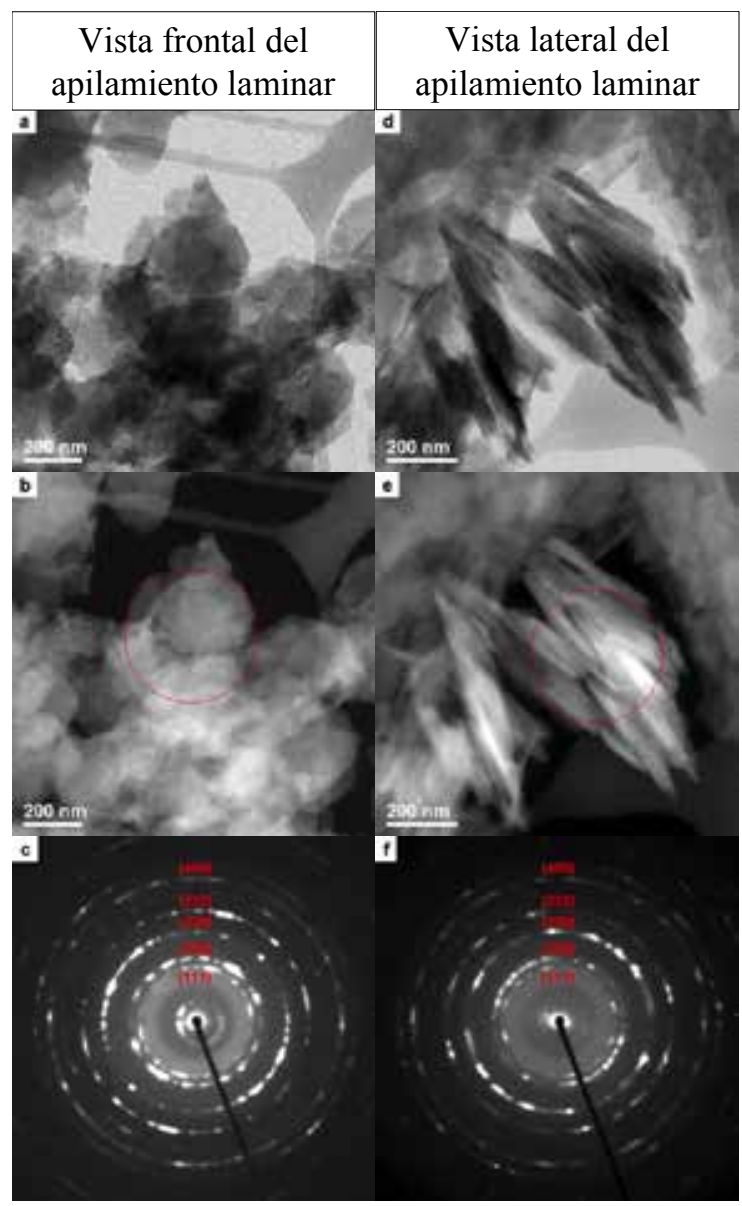

Figura 3. Micrografías STEM de las partículas de $M g O$ apiladas: (a,b y c) vista frontal y (d,e y f) vista lateral. Las imágenes (a) y (d) corresponden a campo claro; (b) y (e) al contraste Z, y luego en (c) y (f) difracción de electrones las zonas indicadas en los círculos de las imágenes en (b) y (e) respectivamente. 
Otra técnica empleada para el análisis de las partículas de $\mathrm{MgO}$ fue incidencia de ángulo rasante para dispersión de rayos X para ángulos grandes, denominada GIWAXS de los términos en inglés grazing incidence wide angle $X$ ray scattering. El equipo GIWAXS empleado fue un XMI LAB equipado con un ánodo rotante Rigaku con una fuente altamente brillante de Fr-E+ operada a 2,5W, acoplado a un sistema CMF 15-105 (K $\alpha)$ de enfoque para altos flujos y una cámara SAXS/WAXS modelo SMAX3000.

Para la preparación de las muestras, se dejó caer una gota de la suspensión de $\operatorname{Mg}(\mathrm{OH})_{2}$ sobre un vidrio portaobjeto, de manera análoga el proceso de modificación de los electrodos de $\mathrm{TiO}_{2}$, luego se procedió a la sinterización a $530^{\circ} \mathrm{C}$. Los análisis se desarrollaron a $0,04^{\circ}$ de incidencia para obtener de la señal la máxima contribución del $M g O$ depositado sobre el sustrato. La figura 4 presenta los patrones GIWAXS 2D y 1D, este último obtenido a través de la integración acimutal del primero. Se puede reconocer en la figura 4a un patrón difuso para valores de x e y $=2,5 \AA^{-1}$, pero a x e y $=3,0 \AA^{-1}$ claramente se presenta un anillo, este patrón típicamente corresponde a material conformado por islas. En la figura $4 \mathrm{~b}$ en el rango de q entre 1,5 y 2,8 se presenta una banda ancha correspondiente a la señal procedente del sustrato, mientras que a $\mathrm{q}=3 \AA$ se distingue claramente un pico asignado al $\mathrm{MgO}$, característico de la reflexión (200) correspondiente a su estructura FCC.

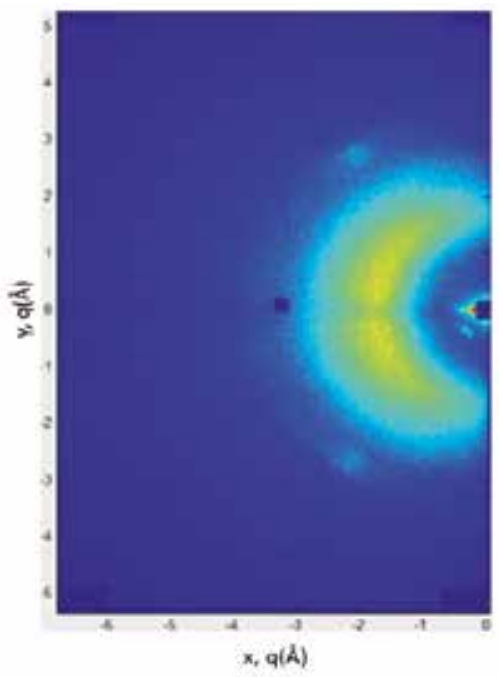

(a)

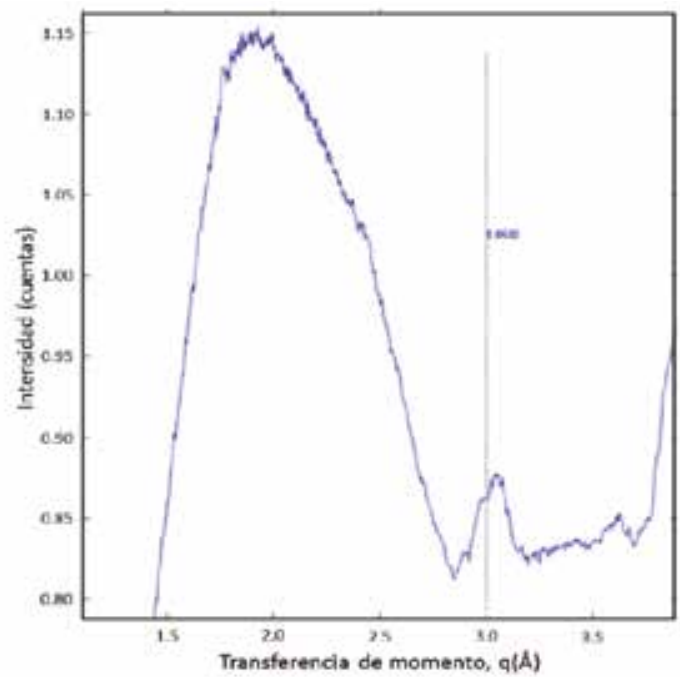

(b)

Figura 4. Patrones GIWAXS 2D (a) y 1D (b) para muestras de $M g O$ depositadas sobre un sustrato de vidrio. 
Eficiencia solar de las celdas construidas con electrodos de $\mathrm{TiO}_{2}$ y $\mathrm{TiO}_{2}-\mathrm{MgO}$

Las evaluaciones como celda solar para electrodos de trabajo modificados se realizó trabajando con suspensiones de $\mathrm{MgOH}$ de diferentes concentraciones. La eficiencia de las celdas se midió en un montaje detallado anteriormente ${ }^{5}$, el cual estaba constituido por una fuente de iluminación de $250 \mathrm{~W}$, un arreglo óptico y un sistema de adquisición de datos. Las medidas se llevaron a cabo a $1000 \mathrm{~W} / \mathrm{m}^{2}$. La figura 5 muestra las curvas corriente-voltaje para las celdas fabricadas, no selladas, con suspensiones acuosas de $\mathrm{MgOH}$ para concentraciones entre 0 y $10 \times 10^{-6} \mathrm{M}$. Se observa claramente que el máximo de densidad de corriente en corto circuito (Jsc), aproximadamente $8 \mathrm{~mA} / \mathrm{cm}^{2}$, se alcanzó para la celda fabricada con la suspensión 2,5x $10^{-6} \mathrm{M}$ de $\mathrm{MgOH}$. Para mayores concentraciones se observa una disminución de la corriente. Los valores de voltaje de circuito abierto (Voc) para todas las celdas se encuentra en el rango entre 0,80 y $0,85 \mathrm{~V}$.

Los valores de Jsc,Voc, FF y eficencia ( $\eta)$, se presentan en la tabla 1.

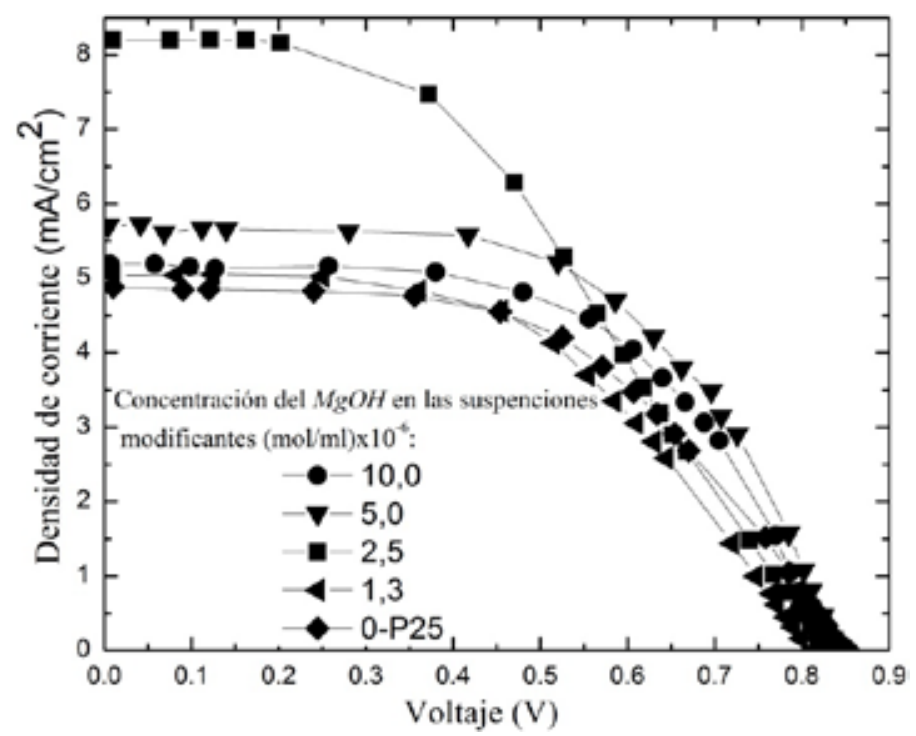

Figura 5. Curvas corriente-voltaje para celdas construidas con electrodos de trabajo $\mathrm{TiO}_{2}-\mathrm{MgO}$ para diferentes concentraciones de $\mathrm{MgOH}$.

Tabla 1. Parámetros de funcionamiento de las celdas solares sensibilizadas modificadas y no modificadas para diferentes concentraciones de $\mathrm{MgO}$.

\begin{tabular}{ccccc}
\hline $\begin{array}{c}\text { Concentración de } \mathrm{MgOH} \\
(\mathrm{mol} / \mathrm{ml}) \times 10^{-6}\end{array}$ & $\mathrm{~J}_{\mathrm{SC}}\left(\mathrm{mA} / \mathrm{cm}^{2}\right)$ & $\mathrm{V}_{\mathrm{OC}}(\mathrm{V})$ & $\mathrm{FF}$ & $\eta(\%)$ \\
\hline $0(\mathrm{P} 25)$ & 4,8 & 0,9 & 0,5 & 2,2 \\
\hline 1,3 & 5,0 & 0,8 & 0,5 & 2,1 \\
\hline 2,5 & 8,2 & 0,8 & 0,4 & 3,0 \\
\hline 5,0 & 5,7 & 0,8 & 0,6 & 2,8 \\
\hline 10,0 & 5,2 & 0,8 & 0,6 & 2,5 \\
\hline
\end{tabular}


Como se mencionó, un aspecto importante de este trabajo lo constituyó el proceso de sellado de las celdas, para ello se trabajó con el electrodo de trabajo fabricado a la concentración óptima de 2,5 x10 $0^{-6} \mathrm{M}$ de $\mathrm{MgOH}$. La figura 6 muestra las curvas obtenidas para las celdas selladas, donde se observa que la celda con el electrodo optimo modificado alcanza una corriente de corto circuito de $\sim 8,5 \mathrm{~mA} / \mathrm{cm}^{2}$, este valor se mantiene casi constante hasta 400 $\mathrm{V}$. La eficiencia para las celdas no modificadas fue de $2,6 \%$ mientras que para las celdas modificadas fue de $4,4 \%$, valor que representó un incremento del $69 \%$. Así, las celdas selladas permitieron alcanzar mayores valores de eficiencias y de tiempos de vida

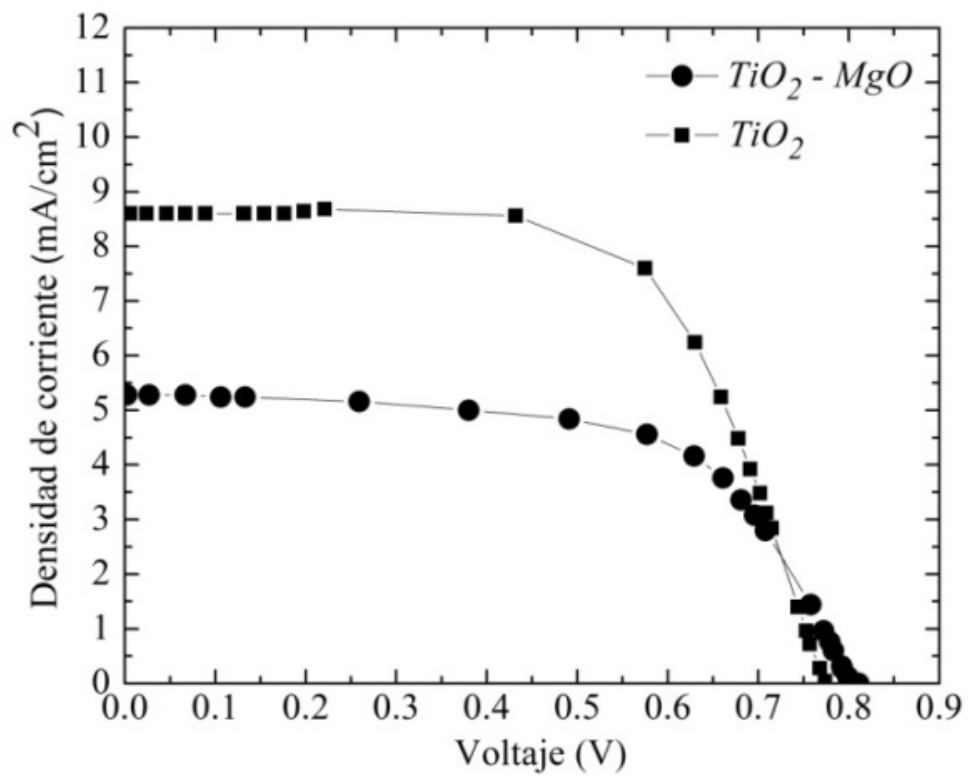

Figura 7. Eficiencia fotón incidente-electrón generado para electrodos de trabajo $\mathrm{TiO}_{2}$ y $\mathrm{TiO}_{2}-\mathrm{MgO}$ óptimo.

Claramente, se observa que en todo el espectro analizado, la respuesta del electrodo modificado óptimo se incrementa hasta en $10 \%$ respecto de la respuesta del electrodo sin modificar.

Otro estudio ejecutado para los electrodos sin modificar y óptimo modificado fue el de voltametría cíclica desarrollado en un sistema redox acuoso de ferricianuro de potasio a una concentración de 0,01 M. Se usó como contraelectrodo un cable de Pt y como electrodo de referencia un electrodo $\mathrm{Ag} / \mathrm{AgCl}$ saturado. Las medidas se realizaron bajo iluminación empleando una lámpara Ultra-Vitalux Osram $(220 \mathrm{~V}$ y $300 \mathrm{~W})$ para un barrido de potencial de $50 \mathrm{mV} / \mathrm{s}$ en un rango de -300 a $800 \mathrm{mV}$. La figura 8 muestra los voltagramas obtenidos para los electrodos de $\mathrm{TiO}_{2}$ y $\mathrm{TiO}_{2}-\mathrm{MgO}$ óptimo. 


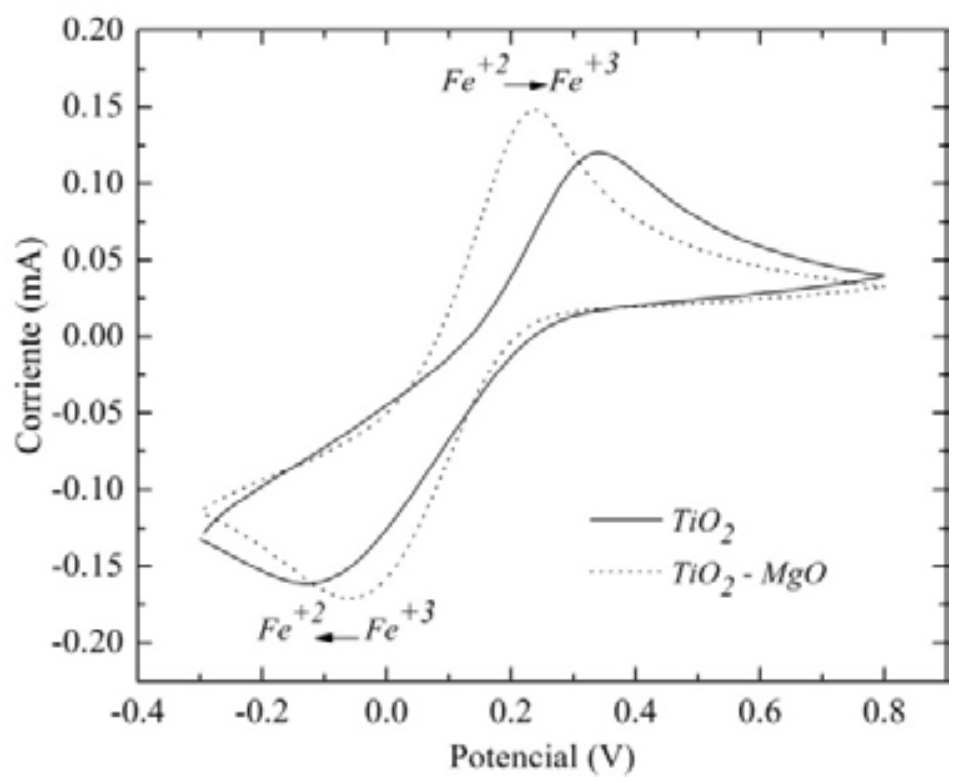

Figura 8. Voltametría cíclica para electrodos de trabajo $\mathrm{TiO}_{2}$ y $\mathrm{TiO}_{2}-\mathrm{MgO}$ óptimo.

Se observa que para el recubrimiento modificado óptimo el pico de oxidación del $\mathrm{Fe}^{+2} \mathrm{se}$ desplaza a menores potenciales, mientras que el pico de reducción del $\mathrm{Fe}^{+3}$ lo hace a mayores valores de voltaje, lo que podría estar asociado a que la presencia del $\mathrm{MgO}$ facilitaría la transferencia de electrones en los procesos redox.

\section{Dependencia de la eficiencia de una celda sellada de $\mathrm{TiO}_{2}-\mathrm{MgO}$ con el tiempo}

Los resultados de exponer una celda sellada a una irradiancia de $1000 \mathrm{~W} / \mathrm{m}^{2}$ se muestran en la figura 9. La celda recién sellada presentó una eficiencia de 5,7\%; luego se mantuvo en oscuridad y se midió su eficiencia luego de dos días y fue de 4,9\%. Después de 20 días mantenida en oscuridad, la eficiencia de la celda tuvo un valor de 4,7\%. Lo que representó una disminución de la eficiencia del 19\%. A partir del día 23 la celda se expuso a iluminación de forma ininterrumpida durante dos días y luego de ese lapso la eficiencia disminuyó hasta $1,1 \%$, que correspondió a una disminución del 75\% de la eficiencia. Para el día 26 nuevamente se apagó la iluminación y se mantuvo la celda en oscuridad durante dos días donde finalmente la eficiencia llegó a 0,8\%. 


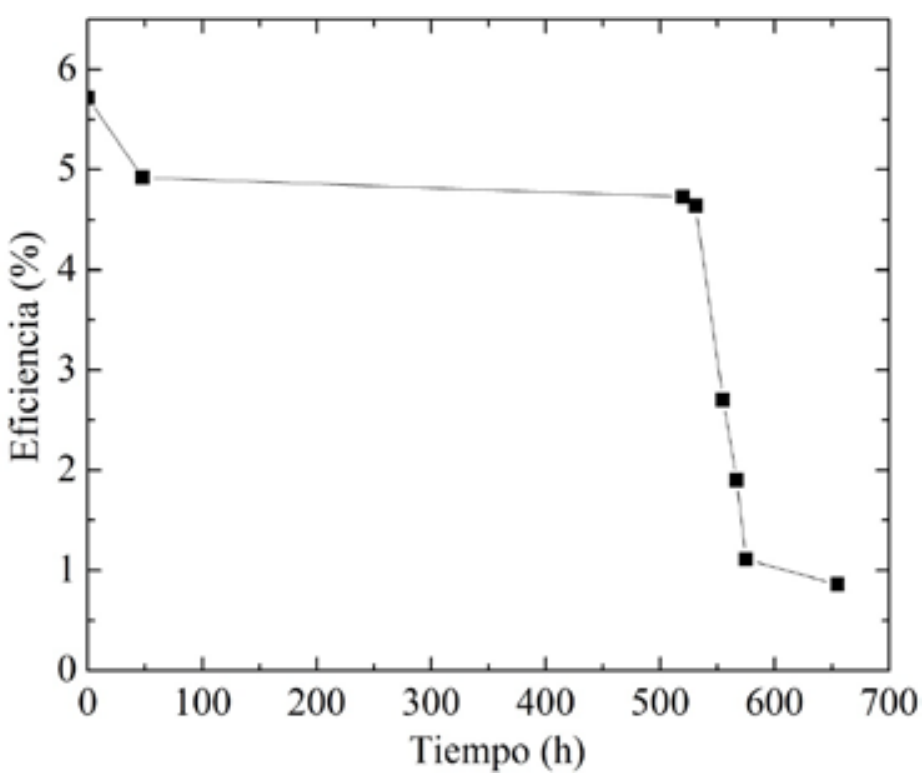

Figura 9. Eficiencia de la celda sellada modificada de $\mathrm{TiO}_{2}-\mathrm{MgO}$ en función del tiempo.

Estos resultados están en concordancia con la degradación observada en celdas similares ${ }^{12}$. La disminución de la eficiencia está asociada básicamente a dos efectos: la descomposición del colorante y la evaporación del electrolito.

Dado que la banda prohibida del $\mathrm{MgO}$ corresponde a valores que aproximadamente se encuentran en $7 \mathrm{eV}^{13}$, se postula que la transferencia de electrones desde el colorante al $\mathrm{MgO}$ se realiza por medio de efecto túnel, mecanismo planteado para otros óxidos ${ }^{4}$ con bandas prohibidas mayores al $\mathrm{TiO}_{2}$. No se espera que se presente mayor modificación del mecanismo de difusión de los electrones hasta el contacto posterior, una vez que alcanzan el $\mathrm{TiO}_{2}$. Estudios adicionales son necesarios para comprobar lo postulado, pero estos estudios no son objetivo del presente artículo.

\section{CONCLUSIONES}

Se fabricaron celdas solares empleando como electrodos de trabajo recubrimientos de $\mathrm{TiO}_{2}$ y $\mathrm{TiO}_{2}-\mathrm{MgO}$. La modificación superficial del $\mathrm{TiO}_{2}$ se realizó usando suspensiones acuosas de $\mathrm{MgO}$ de diferentes concentraciones y se determinó que la mejor eficiencia para celdas no selladas se obtuvo para una concentración de la suspensión de $M g(O H)_{2}$ igual a 2,5 x10 $0^{-6} \mathrm{M}$, que dio un valor de eficiencia de $3 \%$ mayor al valor obtenido para una no modificada que fue de aproximadamente $2,2 \%$, incrementándose en aproximadamente $36 \%$. Las celdas selladas 
presentaron mejores valores de eficiencia. La celda sellada y modificada alcanzó 4,4\%, lo que representó un incremento del $69 \%$ con relación a la celda sellada no modificada.

Se identificó la presencia de $\mathrm{Mg}$ en el electrodo modificado en una cantidad de $149 \mathrm{ppm}$, sin embargo para aproximarse a la estructura y morfología que el $\mathrm{MgO}$ podría presentar en la celda, se determinaron las propiedades de este material en polvo, así como del material obtenido al depositar la suspensión de $\mathrm{Mg}(\mathrm{OH})_{2}$ sobre un sustrato de vidrio. Ambos materiales fueron obtenidos empleando las mismas condiciones de sinterización que los electrodos modificados. Para el caso del estudió del polvo de $\mathrm{MgO}$ se halló un tamaño de dominio cristalino de $\sim 16 \mathrm{~nm}$ con conglomerados cristalinos de $\sim 200 \mathrm{~nm}$ de morfología laminar. Mientras que para el $\mathrm{MgO}$ depositado sobre vidrio se confirmó que presentó una texturización con orientación preferencial en la dirección (200), corroborando los datos obtenidos por DRX y TEM.

Dado que la aplicación del $\mathrm{Mg}(\mathrm{OH})_{2}$ es superficial se espera que las partículas de $\mathrm{MgO}$, formadas durante el proceso de sinterización, se ubiquen predominantemente en la superficie del electrodo, lo que disminuiría procesos de recombinación en la interface electrodo de trabajo-electrolito.

\section{AGRADECIMIENTO}

M.M.G. agradece al Instituto General de Investigación de la Universidad Nacional de Ingeniería (IGI-UNI) por la financiación individual recibida. Se agradece a NANOTECH (CIMAV-Chihuahua) por las facilidades brindadas en microscopía electrónica. Se agradece al Dr. Alcides López por el análisis de FRX. Este trabajo ha sido desarrollado gracias al auspicio recibido por CONCYTEC (Contratos 239-2011, 406-2012, 040-2013), y The World Academy of Sciences (TWAS).

\section{REFERENCIAS BIBLIOGRÁFICAS}

1. Lokhande AC, Chalapathy RBV, He M, Jo E, Gang M, Pawar SA, et al. Development of $\mathrm{Cu} 2 \mathrm{SnS} 3$ (CTS) thin film solar cells by physical techniques: A status review. Sol Energ Mat Sol Cells. 2016; 153:84-107.

2. O'Regan BC, Grätzel M. A low-cost, high-efficiency solar cell based on dye-sensitized colloidal $\mathrm{TiO}_{2}$ films. Nature. 1991; 353: 737-740.

3. Grätzel M. Dye-sensitized solar cells. J Photochem Photobiol C: Photochem Rev. 2003; 4(2):145-53.

4. Chou C-S, Lin Y-J, Yang R-Y, Liu K-H. Preparation of $\mathrm{TiO}_{2} / \mathrm{NiO}$ composite particles and their applications in dye-sensitized solar cells. Adv Powder Technol. 2011; 22(1):31-42.

5. Galicia M, Solis JL, Gómez MM. Fabricación y caracterización de celdas solares sensibilizadas de $\mathrm{TiO}_{2}$ modificado con nanopartículas de NiO. Rev Soc Quim Perú. 2016. 81(1): p. 87-99. 
6. Chou C-S, Chou F-C, Kang J-Y. Preparation of $\mathrm{ZnO}$-coated $\mathrm{TiO}_{2}$ electrodes using dip coating and their applications in dye-sensitized solar cells. Powder Tech. 2012;215216:38-45.

7. Senevirathna MKI, Pitigala PKDDP, Premalal EVA, Tennakone K, Kumara GRA, Konno A. Stability of the $\mathrm{SnO} / \mathrm{MgO}$ dye-sensitized photoelectrochemical solar cell. Sol Energ Mat Sol Cells. 2007; 91(6):544-7.

8. Habibi MH, Parhizkar J. Cobalt ferrite nano-composite coated on glass by Doctor Blade method for photo-catalytic degradation of an azo textile dye Reactive Red 4: XRD, FESEM and DRS investigations. Spectrochim Acta A Mol Biomol Spectrosc. 2015; 150:879-85.

9. Martinez VC, Matejova L, López A, Cruz G, Solís J, Gómez M. Obtención de Partículas de $\mathrm{TiO}_{2}$ por Sol-Gel, Asistido con Ultrasonido para Aplicaciones Fotocatalíticas. Rev Soc Quim Perú. 2015; 81(3): 201-211.

10. Young RA. The Rietveld Method. Oxford, New York: Oxford University Press; 1995. $312 \mathrm{p}$.

11. Stokes AR, Wilson AJC. A method of calculating the integral breadths of DebyeScherrer lines. Math Proc Camb Philos Soc. 1942;38(3):313-22.

12. Nour-Mohhamadi F, Nguyen SD, Boschloo G, Hagfeldt A, Lund T. Determination of the light-induced degradation rate of the solar cell sensitizer N719 on TiO2 nanocrystalline particles. J Phys Chem B. 1 de diciembre de 2005;109(47):22413-9.

13. Taurian OE, Springborg M, Christensen NE. Self-consistent electronic structures of $\mathrm{MgO}$ and SrO. Solid State Commun. 1985;55(4):351-5. 